\title{
Alienation and Risk: Perspective and Reflection About the Network Presentation of the Image of Female Workers in the Context of COVID-19
}

\author{
Wang Qianru ${ }^{1, *}$ \\ ${ }^{1}$ Institute of Political Science and Law, Jinan University, Jinan, Shandong 250022, China \\ *Corresponding author.Email:1329364947@qq.com
}

\begin{abstract}
In the context of the COVID-19 epidemic, images of female workers are widely presented on the Internet. On the one hand, the persistence and commitment of the female workers in the front line of the fight against the epidemic overturned the traditional image of women, which played a significant role in the elimination of female stereotypes and the building of positive images. On the other hand, under the influence of traditional patriarchal culture, consumer culture and female stereotypes, there is still a certain degree of alienation in the representation of female workers in many reports, which will eliminate women's subjectivity in an invisible way. Mainstream media and women themselves should make efforts to eliminate gender discrimination as far as possible, create an equal and just network ecological environment, and promote harmonious relations between the sexes.
\end{abstract}

Keywords: COVID-19 epidemic; female workers; network society; image presentation

\section{INTRODUCTION}

Since December 2019, COVID - 19 outbreak from the rapidly expanding to Wuhan, across the country have to carry out the comprehensive disease prevention, network media for COVID-19 outbreak reported Numbers of blowout growth, disease resistance to work in a line workers become the focus of media attention from all walks of life, including a significant number of women workers. As a sudden large-scale public health events, it threatened the life safety of the national people's vital and interests, and thus received widespread attention, disease resistance to work in a line of women workers, through the network media reported being present and a positive image for the elimination of female stereotypes and shape play a considerable role. But still it is worth noting that under the background of COVID-19 outbreak many network report for female image rendering still exists a certain degree of alienation, alienation of the female image will appear in virtually eliminate the subjectivity of the female, women in a still suck people eyeball "viewed" status, peculiar to the female workers under the network media professional spirit and professional ability are neglected, as a female gender roles and gender characteristics of the main content of network media reports, the partial rendering of female images, female image and identity that is another kind of distortion and alienation. Stereotypes of female images exist for a long time, female images in the traditional media, more is neglected and partial rendering, the Internet gives female image more show provides a new platform and channel, with the rise of the network society, the female image of the network, and the thinking about gender equality, has always been a problem widely concerned by academic circles. The purpose of this paper is to analyze the content of online media reports on Sina, Tencent and other platforms under the background of COVID-19, to discuss the network appearance of female workers' images and its influencing factors, and puts forward corresponding Suggestions on relevant issues.

\section{RELEVENT LITERATURE REVIEW}

Through sorting out the relevant literature on the network presentation of female images, it is found that the research on the network presentation of female images mainly includes two aspects: the active presentation of female individuals on social media platforms, and the shaping and presentation of female images by online media.

Firstly, it is an analysis of the present situation of female image network. Some scholars believe that female images in the network appear more in the role images of mother and wife, that is, a typical traditional gender pattern with male dominant and female auxiliary and male strong and female weak ${ }^{[1]}$. At the same time, women are still in a position of being seen as an object. The gender identity of women is highlighted in the network, and women are still the target of sexual desire ${ }^{[1]}$. Driven by consumption and commercial interests, many commodity advertisements apply female body in the packaging of commodities or secretly induce the audience to accept the sexual connotation of female image as far as possible, making the female image gradually evolve into an "object" for men to watch and consume (entertainment) ${ }^{[2]}$. Some scholars believe that the rise and development of the Internet has 
given women more opportunities to participate in media construction. Women, especially female celebrities who have rapidly gained popularity in recent years, have gained certain discourse power through Internet media. As a platform to fully display themselves, the Internet has played a very good role in promoting the enhancement of women's consciousness and the improvement of social status ${ }^{[3]}$.

Second, many scholars have discussed the factors that influence the appearance of female image network, which generally include three aspects, namely, social, historical and cultural factors, women's own factors, and consumption and market factors. First of all, the Internet does not make women get rid of the marginal role of weakness. As a new tool and technology, the Internet is still in the hands of men ${ }^{[1]}$. Thousands of years of Chinese male mainstream culture makes women just under the male subject view the objectification of the object, is "the other", women become more of a symbol was written by men and shaping, and lead to women's collective unconscious, active to cater to the viewer's eye with his body and the viewer's standards and requirements to achieve ${ }^{[4]}$. The expansion of consumerism is also an important factor affecting the presentation of female images. Consumers regard the consumption of goods as a symbol of a particular social status, status and class, and a large number of female images are often used in advertisements as "perceptual" interpretation of the symbolic characteristics of goods ${ }^{[2]}$.

Summary, the network medium long-term of women is more young and beautiful, or is the wife and mother type woman, catering to the men's taste and demand the commercialization of consumerism, in the interests of the consumer and market driven, female images in the network is "use" and gradually lose its autonomy, gradually become the male culture and consumption culture of accessories and lost its independence.

COVID - 19 outbreak belongs to the important social and public events, is closely related to people's life, by the national people's high attention, the outbreak has most of the people were confined to families, communities, such as closure of physical space, corresponding caused unprecedented active network space, people pay close attention to the network media for outbreaks reported, at the same time accept the network for the vast number of female image shaping, then, under the background of special new crown outbreak, under the background of this sudden large-scale public events, the image of women workers how to present in the network, and the previous network appear what's the difference? What factors will affect the network presentation of female images? What should society, media and individuals do to ensure the objectivity of female images? It is the main content of this paper.

\section{THE STATUS OF ONLINE PRESENTATION OF FEMALE IMAGES UNDER THE COVID-19 EPIDEMIC}

\subsection{Positive presentation of female images in the context of the epidemic}

In the context of the COVID-19 epidemic, female workers on the front line are undoubtedly the focus of the online media. In the context of the comprehensive fight against COVID-19, mainstream media have praised and praised female workers on the front line, who have undoubtedly played an important role in the fight against the epidemic. Through to January to April, 2020 sina news content analysis, can be found in female workers against epidemic report mainly includes individual and group reported two forms, represented by Lanjuan $\mathrm{Li}$, outstanding deeds of women workers as the theme, show it's contribution for the work of resistance to disease and spirit of sacrifice. It can be seen that during the COVID-19 epidemic, the coverage of female images has reached a certain extent in both quantity and scope, and online media and all parties have shown a certain degree of concern and positive comments on women. Different from the traditional "symbolized" and "tagged" female images, the network of female images under the COVID-19 epidemic is more three-dimensional, more frequent and more vivid.

\subsection{The alienation of female images in the context of the epidemic}

In the context of the epidemic, the online media focus on all kinds of staff on the front line of the fight against the epidemic, and the reports of female staff are often also widely concerned or even controversial. The image of women workers were present on the Internet there are many problems in the process, first of all, there are, according to support the front line of women workers accounted for about two-thirds of the total number of staff, however, in the actual process of propaganda, medical workers have more glorious image appears to men, women present only occupy a small fraction of the proportion. Secondly, female workers are often shown in groups, focusing on the emotional color and physical sacrifice of female workers under the epidemic, while ignoring the actual needs brought about by it. Finally, in order to highlight the hardship and solemn and stirring color of the frontline anti-epidemic work under the epidemic, a series of reports such as "shaved head", drug weaning, pregnant mother going to the front line, ten days after abortion insisted on going to the front line and so on were overpaid attention to and propagated, rendering a strong heroic color of tragic type in wartime.

From the perspective of the theory of alienation, under the background of new crown outbreak, on the one hand, the female image has been widely reported, on the other hand, 
women in the present network is still in a suck people eyeball "viewed" status, peculiar to the female workers under the network media professional spirit and professional ability are neglected, the image is still focused on traditional family role as a wife, mother, as a "female" by the sacrifice was part of the rendering of the body and description, does not seem to concern their wisdom and ability. There is no doubt that this kind of report deviates from the demands of women in the new era for the presentation of independent and subjective images. In terms of network presentation, women still present an absent presence.

\section{REASONS FOR THE ALIENATION OF FEMALE IMAGE NETWORKS UNDER THE NEW CROWN EPIDEMIC}

\subsection{The influence of traditional patriarchal culture}

Gender theory believes that the root of the division of labor between the sexes is not due to innate physiological differences, but in the shaping of acquired social systems and culture, which is gradually formed by individuals through imitation and learning in the process of socialization. The division of labor between the sexes has caused differences in the social roles and social status of men and women, making men and women subject to different standards and constraints. Chinese society has long been dominated by the patriarchal culture that men are superior to women, and men dominate and assist women. As the name suggests, traditional patriarchal culture is a culture centered on men, with a masculine value orientation and power center. Women are often male. Accessories are controlled and dominated by men. With the transformation of social values and the increase in tolerance, gender equality has developed to a relatively high level. Contemporary women have a higher degree of autonomy, but they are not completely Getting rid of the influence of patriarchal culture is reflected in all aspects of daily life. The current online media' $\mathrm{s}$ value orientation is still influenced by the patriarchal culture of traditional society. "Males dominate outside, women dominate inside." Men are in the foreground, women are in the background, and they cannot easily show up. Women are always in a marginalized position. Ignored, for example, in the promotional photos of some anti-epidemic heroes, female images are rarely presented, or are they in a relatively marginal position.

\subsection{Female stereotypes that are difficult to change}

The influence of factors such as traditional culture, values, and the division of labor between the sexes has formed a stereotype of women for a long time. The stereotype of women has existed for a long time and spread in cyberspace, and is reflected in the presentation of female images on the Internet. In the era of online media, female stereotypes have been brought to the extreme, "feminine characteristics" have been repeatedly emphasized and expanded, and women's subjectivity has been seriously ignored ${ }^{[5]}$. The presence of female workers on the Internet in the context of the epidemic also cannot escape the barriers of long-standing popular media stereotypes. In related reports, female characteristics are highlighted to attract attention. Under the epidemic, her physical sacrifice as a "female" has received special "favor" from online media to maximize the sympathy and touch of viewers, and then gain a wider range of attention. Stereotypes make the online presentation of female workers' image still unavoidable. In the epidemic situation, the online presentation of female workers is often gentle and patient, with obvious emotional attraction, and arouses the sympathy, compassion and sympathy of the audience. Moved, women should be individuals with subjectivity and independent personality, and they tend to be flat and one-sided in the actual network presentation. Female images can be gentle, delicate, and emotional, but at the same time Especially the strong, brave and intelligent side, especially in the actual professional field and work, the female image in the process of network presentation should not only serve as an auxiliary foil.

\subsection{Long-term disciplined female body and image}

Foucault believes that modern disciplinary methods are different from previous methods of violent punishment. They are often done in a way that allows the body to feel tangible benefits. The society encourages the behaviors it recognizes. If people do not recognize it. The behavior will be pressured by morality and public opinion. Foucault's

"discipline" theory can also explain the current online presentation of female images. Social power is still concentrated in the hands of men. This power acts on women's bodies and behaviors in a more concealed manner. Set specific standards and requirements. Under the background of the epidemic, the behavior of female medical workers to shave their heads is often a kind of "voluntary" behavior, a helpless choice that has to be made due to various pressures.

Women have long been in a position of being objectified and stared at. In traditional media, female images are mainly presented for the purpose of attracting eyeballs. The online media is often not interested in women's work or real daily life, but the female body, especially It is selfsacrifice represented by the body. Feminist theory believes that this is caused by gender inequality in social systems and culture. The news that female medical workers asked to have their heads shaved before they came to the front was widely reported and eye-catching. Few people could think of whether such measures were necessary. At the 
same time, this kind of publicity and reporting has encouraged and deepened this behavior, and caused greater physical and psychological pressure on female medical workers. This still reflects the reality of gender inequality. The same medical workers on the front line have not made similar demands on men.

\section{CONCLUSIONS AND RECOMMENDATION}

In the context of the COVID-19 epidemic, the image of female workers has been widely reported on the Internet, attracting attention and controversy. On the one hand, the outbreak of the new champions league against the front as if set up a different display platform, present the female strong and brave, professional brand image, so many women workers stand in the forefront of resistance, and the positive women present network overturns the traditional vulnerability, shaping, shows the contemporary women's sense of responsibility and power, proved the women not only can only stay at home or do some simple auxiliary work behind the scenes, this to upgrade the image of women, eliminate gender discrimination has a strong role in promoting., on the other hand, some of the network media has long been the influence of traditional culture and interests oriented mindset, the outbreak of women workers has failed to adequately objective reporting, making female workers image rendering is still exist alienation, this kind of alienation phenomenon not only can't change the society for women's long-standing stereotype, for promoting harmonious relationships will also is bad.

\subsection{Build the network environment of real gender equality}

The network media should pay attention to the correct guidance of public opinion, devote themselves to shape the objective image of both sexes, and show more diversified and objective female images. On the one hand, the media practitioners should establish the correct concept of gender equality, for the construction of gender equality to play a more positive role of network ecology, such as under the background of the outbreak, the image of the female medical workers should not be limited to have been tired and ruined face, be sacrificed, body health, and should be more presents them as doctors, nurses, have professional knowledge, ability and wisdom, in the field of professional and working on, they and no difference in men; On the other hand, women should also cultivate their own independent personality, think independently, and become the subject in the real sense of modern society, giving full play to their unique values, instead of drifting with the tide under the drive of interests and becoming "materialized" existence to please others.

\subsection{Construct the real environment of gender equality}

The network is often the projection of reality, and the network presentation is undoubtedly influenced by social culture and the mindset of realistic people, thus stereotyping is often generated. First of all, the construction of harmonious social relations between men and women is inseparable from the system and publicity, and inseparable from the adjustment and popularization of objective and just social value system. China's patriarchy culture, which has lasted for thousands of years, has a profound influence on its people. At present, people still cannot be completely separated from its influence, and the process of achieving complete gender equality cannot be accomplished overnight. It requires persistent pursuit and efforts, the correct guidance of the government and social organizations, and the conscious and active acceptance of the people. Secondly, women themselves should also "increase power", enhance their independent spirit and self-subject consciousness, think independently, and establish their discourse power and social participation.

We should dialectical view, the female image in cyber space, on the one hand, people can feel a woman indispensable important role in various areas, on the other hand, the female image in network rendering still cannot get rid of the position is to see, a lot of time cannot be objective, outbreak presents the image of women under the background of cyberspace should be diversified and the objective, the network is always starts its inherent characteristics of flat, as a public network, more should be more alert and rational view of women in the network all kinds of present.

\section{REFERENCES}

[1] Wang Xiaobo. Networking and Gender Structure[J]. Tianjin Social Sciences, 2005(01). DOI : 10.16240/j.cnki.1002-3976.2005.01.017

[2] Su Biliang, Xie Huiying. The alienation of female images in commercial advertisements [J]. Contemporary Communication, 2008 (04).

[3] Wang Lei. Internet media communication from the perspective of feminism: Taking Internet heroines as an example to discuss women' s expression[J]. Journal of Henan University (Social Science Edition), 2011, 51(02). DOI: 10.15991/j.cnki.411028.2011.02.015

[4] $\mathrm{Gu}$ Junxia. Visual women and female vision[J]. Journal of Chongqing Institute of Technology (Social Science Edition), 2007(04).

[5] Zhang Hengjun. Criticism of Female Stereotypes in Contemporary Media[J]. Journalism, 2012(01). DOI: 10.15897/j.cnki.cn51-1046/g2.2012.01.007 